\title{
Health Psychological Case Study of High Intensity, Low Impact, Physical Training Program
}

\author{
Stephen D. Edwards ${ }^{1}$ \\ ${ }^{1}$ Psychology Department, University of Zululand, Private Bag, X1001, KwaDlangezwa 3886, South Africa \\ Correspondence: Stephen D. Edwards, Psychology Department, University of Zululand, Private Bag, X1001, \\ KwaDlangezwa 3886, South Africa. E-mail: sdedward@telkomsa.net
}

Received: May 26, 2018 Accepted: February 19, 2019 Online Published: November 30, 2019

doi:10.5539/gjhs.v12n1p1 URL: https://doi.org/10.5539/gjhs.v12n1p1

\begin{abstract}
This case study reports on the health psychological evaluation of an integrated, high intensity, lo impact, physical training program for a 31 year old, male accountancy teacher. High intensity components consisted of running, cycling and the Canadian Airforce 5BX program. Low impact components comprised walking and Chi-gung inspired Pilates. Squash and swimming were also occasional activities. The pre-test and post-test, process and outcome evaluative, research design included qualitative and quantitative components in the form of psychometric testing, diarizing of physical activity, experiential descriptions of the various components and program outcome evaluation. Quantitative findings indicated significant improvements in psychophysiological coherence, mood, resilience and general health. Qualitative experiential descriptions provided further evidence of health psychological growth. Integrative findings emphasize the importance of physical training programs based on client individual preferences. The client reported that he found the program to be enjoyable, flexible, invigorating and readily adaptable to suit the needs of various individuals who face time and space constraints in their daily lives. With minimal innovation for greater complexity, control and/or challenges, such programs may readily yield enjoyable flow experiences.
\end{abstract}

Keywords: health psychology, case study, high intensity, lo impact, physical training.

\section{Introduction}

Health and physical activity essentially involve diverse arrays of energy corresponding to dynamic, organ systems, human social behavioural patterns and correlated, environmental resonant frequencies (Childre, Martin, Rozman \& McCraty, 2016). In this case study, health is viewed as a coherent, dynamic integrity of various interacting dimensions and contexts (Childre et al., 2016; Wilber, 2000). Physical exercise refers to planned and purposeful forms of physical activity aimed at promoting health, wellness and/or performance as hierarchically developed and harmoniously tailored to suit individual and/or collective values, needs and training progression principles (Edwards \& Fox, 2005).

Many studies using quantitative, qualitative, mixed and integrated methods have clearly demonstrated the health psychological effectiveness of physical exercise, particularly in preventing stress, anxiety, anger and depression, and especially in the case of regular, moderate intensity exercise interventions, where the type, intensity and duration of interventions are tailored to suit the particular exercisers (Kwan, \& Stevens, 2017: Sharkey, 2016) Studying desirable changes in mood and meaning in exercise programmes, health promotion researchers have generally emphasized regular, non-competitive movement involving 20 to 30 minutes duration in comfortable, predictable contexts as in Pilates, Yoga, Alexander technique, Chi-gung, aerobic exercise, dance and resistance training performed in a slow, controlled way (Balk \& Shields, 2016; Kwan \& Stevens, 2017). Public health interventions clearly need to take individual preferences and personal meanings into account, as people will repeat behaviours that are intrinsically rewarding (Edwards \& Fox, 2005).

Cross-training theory, principles and practices have complementary value in health, sport and exercise contexts (Noakes, 2011). High intensity training (HIT) and low impact (LO) physical exercise programmes have become increasingly popular for various reasons, including small time requirements, stress relief, physiological effectiveness, low injury risk and sustainability (Biddle \& Batterham, 2015). Most studies have examined physiological benefits of HIT programmes, especially high intensity interval training (HITT) and to a lesser extent, those of LO training, especially aerobics (Hoydal \& Hareide, 2016). Although fewer studies have examined the psychological effects of such programmes, these have also been recognized. (Mastura, Fauzee, Bahaman, \& 
Somchit 2012; Rokka, Mavridis, \& Kouli, 2010).

\subsection{Aim}

The aim of the present case study was to evaluate the health psychological effects of a high intensity, low impact training program on a 32 year old man, currently employed as an accountancy teacher at a local, private, educational college. The client sought health psychological consultation with specific goals of improving his health, resilience and mood through an exercise program, appropriate for his particular height, weight and individual exercise preferences. He had been involved in a running program but had developed knee problems related to right knee peripatelar pain syndrome (runner's knee). This was associated with tendency to splay the right foot compounded by his particular height $(186 \mathrm{~cm})$ and weight $(90 \mathrm{~kg})$ characteristics.

\subsection{Research Questions and Hypotheses}

The applied therapeutic research questions were essentially exploratory in nature and may be formulated as follows: What particular health psychologically orientated exercise program would be valuable for this particular client? What particular components would be most suitable? In view of evidence as to the psychological effectiveness of beneficial helping relationships as well as health orientated exercise programs, it was hypothesized that client health psychological coaching in support of an individually tailored exercise programme would be optimally effective for this particular client.

\section{Methodology}

Case study research methods are perennially popular in psychological literature because they are descriptive, detailed, longitudinal, and contribute to further research through introducing novel ideas, critical reflection, hypotheses testing, quantitative, qualitative, mixed and integrative methods, theory building and testing (Fetters, Curry \& Creswell, 2013; Ridder, 2017; Starman, 2013; Terre Blanche, Durrheim, \& Painter, 2006). The present pre-test and post-test, case study design included concurrent and convergent design principles of collecting both quantitative and qualitative data, in the form of psychometric testing and qualitative experiential descriptions. Quantitative data consisted of psychophysiological readings on HeartMath emWave2 equipment, complemented by responses to psychometric measures of health, resilience and mood, at both pre-testing and post-testing phases. Qualitative data consisted of experiential descriptions recorded during pre-test, client journaling of experiences during the counselling process and outcome evaluation at the post-test phase after three months of the programme. As typically of case studies, communication, relationship and training program variables formed integral, necessary and sufficient components of the greater, ultimate, wholeness of the research intervention.

Coherent communication lead to the establishment of an empathic, ultimately excellent client-counsellor relationship, which will be described later under the integrative evaluation section. Following in depth discussion, it was eventually decided to try, monitor, pre-test test and post-test the following program: high intensity components consisted of: interval cycling, limited running at a gradient and on sand, an adapted version of the Canadian Airforce 5BX exercises; low impact components consisted of Pilates using a Swiss ball, Alexander technique for postural issues and chi-gung (Tao-yin) for kinaesthetic awareness, core strength and suppleness. A typical weekly program with built in flexibility to suit daily preferences and weather included either steady stationary bike cycling (spinning) interspersed with full exertion speed bursts (about 6 bursts), running, 5BX exercises, singly or combinations thereof. Low impact exercises involving walking, chi-gung or Pilates, in varying patterns, typically took place singly or after high intensity training components. It was decided to use the ten point Borg rating scale of perceived exertion as client subjective process measure of intensity (Borg, 1982; Borg, Borg, Larsson, Letzter, \& Sundblad, 2010) and the Consultation and Relational Empathy (CARE) measure to evaluate the client coach relationship. This is a Likert type scale with 10 items ranging from "poor" to "excellent" and also includes a "does not apply" rating. (Mercer, Watt, Maxwell, \& Heaney 2004). In addition to these process and outcome, assessment and evaluation measures, the following psychophysiological and psychometric instruments were chosen for purposes of pretesting and post-testing before and after the physical training program respectively.

\subsection{Instruments}

The HeartMath tool, emWave2, served as a general Heart Rate Variability (HRV) assessment instrument for psychophysiological coherence, health, resilience and mood. This instrument with complemented by specific psychometric measures of health, resilience and mood. These instruments are described in more detail as follows:

Heart rated variability (HRV) derived psychophysiological coherence was measured with five minute recordings on the HeartMath biofeedback tool, emWave2. In this case five minute recordings of coherence as well as accumulative coherence points were chosen for pre-test and posttest purposes. Psychophysiological coherence is characterized by a heart rhythm pattern of elevated amplitude in low frequency heart rate variability of around 0.1 $\mathrm{Hz}$, accompanied by positive emotions, indicating harmony between sympathetic and parasympathetic divisions of 
the autonomic nervous system. It is experienced as a state of relaxed alertness, which sportspersons describe as "being in the zone" (Childre et al., 2016) an enjoyable state of consciousness similar to what Csikszentmihalyi (1990) has described as "flow".

The Profile of Mood States (POMS) was initially developed as an "economical method of identifying and assessing transient fluctuating affective states" (McNair, Lorr, \& Doppleman, 1971, p. 5), with special reference to the therapeutic relationship. The original scale consisted of sixty-five adjectives rated along a five point intensity scale with special focus on anxious sad, confused, angry, sad, and, the odd one out, energetic feelings. A very short six item POMS (Dean, Whelan. \& Meyers, 1990), which was used in the present study, is a valuable, quick way to assess these same mood states, in addition to a cumulative score of positive mood as derived from reverse scoring negative phrased items related to the abovementioned feelings.

The Brief Resilience Scale (BRS) (Smith, Dalen, Wiggins, Tooley, Christopher, \& Bernard, 2008) has 6 items, which are equally positively and negatively phrased, along a 5 point Likert scale, with requested answers ranging from "strongly disagree" to "strongly agree". Cronbach's alphas for the BRS in six samples were found to be .836, .902, .877, .798, .754 and .702 (Smith, Epstein, Ortiz, Christopher, \& Tooley, 2013).

The General Health Scale consisted of an adaptation of the General Health Questionnaire (GHQ-12), which is intended to screen for general psychiatric morbidity. It has been widely used internationally, and, as a result, translated into many languages and extensively validated in general and clinical populations worldwide. A recent study conducted in the United Kingdom indicated that reliability of this model was over-estimated by the reported Cronbach Alpha of 0.90 for the Likert scoring method and that a more realistic estimate of reliability was 0.73 (Hankins, 2008). The adapted version used in the present study consisted of 12 items, 6 positively phrased and 6 negatively phrased, with a four point Likert scale, ranging from 1 to 4 , requiring responses of strongly agree, agree, disagree and strongly disagree, respectively.

\subsection{Data Analysis}

Quantitative data were analyzed using the computer based Statistical Package for the Social Sciences (SPSS), with specific reference to descriptive, nonparametric statistics for the ppsychophysiological and psychometric measures.

\subsection{Ethics}

University and private practice ethical clearance and client's informed, written consent were obtained.

\section{Results}

Results are reported in terms of quantitative, qualitative and integrative findings, all of which point to the effectiveness and value of the individually tailored and monitored, health and sport psychological intervention focussed on high intensity and low impact physical activity.

\subsection{Quantitative Findings}

Table 1. Psychophysiological coherence and psychometric test measures

\begin{tabular}{llll}
\hline Psychometric and Psychophysiological Coherence Measures & & Pre-test & Post-test \\
\hline Psychophysiological State emWave2 five minute recording & Coherence level & 1.1 & 4.3 \\
& Achievement level & 69 & 242 \\
& Anxious & 3 & 5 \\
& Sad & 4 & 5 \\
Profile of Mood States & Confused & 4 & 5 \\
& Angry & 3 & 4 \\
& Energetic & 3 & 3 \\
\hline Resilience & Tired & 2 & 19 \\
\hline Health & Total Positive Mood & 27 \\
\hline Statistical & & 17 & 25 \\
\hline
\end{tabular}

Statistical Evaluation Wilcoxon Signed Ranks Test $\mathrm{Z}=2.83, \mathrm{p}=.005$. 
Table 1 provides highly significant, quantitative psychophysiological and psychometric evidence as to the effectiveness of the health psychological program. The HRV derived measure of psychophysiological coherence indicated marked increases in coherence level and achievement score. This indicates improved autonomic nervous system functioning as supported by associated increases in the psychometric measures, reflecting (reverse scored) decreases in anxiety, sadness, confusion, anger and tiredness as well as (normally scored, increases in energy and generally positive mood. Such improved HRV coherence indicators are also associated with improved adaptation and well-being as corroborated by the respective psychometric measures of resilience and health.

Table 2. Client process record of high intensity lo impact physical activity programme

\begin{tabular}{|c|c|c|c|c|c|c|c|c|}
\hline \multirow{3}{*}{ Date } & \multicolumn{8}{|c|}{ Month } \\
\hline & \multicolumn{2}{|l|}{ February } & \multicolumn{2}{|l|}{ March } & \multicolumn{2}{|l|}{ April } & \multicolumn{2}{|l|}{ May } \\
\hline & Exercise & Time & Exercise & Time & Exercise & Time & Exercise & Time \\
\hline 1 & & & $*$ & & Cycle & 15 & $\begin{array}{l}\text { 5BX program core } \\
\text { component }\end{array}$ & 30 \\
\hline 2 & & & $*$ & & 5BX program with walk & 30 & Pilates & 40 \\
\hline 3 & & & $*$ & & Pilates & 40 & Swim & 20 \\
\hline 4 & & & $*$ & & & & Run on promenade & 30 \\
\hline 5 & 5BX program & 20 & $*$ & & & & Run in park & 20 \\
\hline 6 & Wet Sand Running & 20 & $*$ & & $\begin{array}{l}5 \mathrm{BX} \text { program followed } \\
\text { by running }\end{array}$ & 30 & Rest & \\
\hline 7 & Pilates & 30 & $*$ & & $\begin{array}{l}\text { Running in the park with } \\
\text { dog }\end{array}$ & 20 & $\begin{array}{l}5 \mathrm{BX} \text { program followed } \\
\text { by cycle and cycle }\end{array}$ & 45 \\
\hline 8 & $\begin{array}{l}\text { Cycle with 5BX } \\
\text { program }\end{array}$ & 30 & $*$ & & $\begin{array}{l}\text { Cycle with incline } \\
\text { running }\end{array}$ & 30 & Run on sand & 20 \\
\hline 9 & $\begin{array}{l}\text { Walk with dog and } \\
5 \mathrm{BX} \text { program }\end{array}$ & 30 & $*$ & & $\begin{array}{l}\text { Cycle followed by sand } \\
\text { run }\end{array}$ & 40 & $\begin{array}{l}\text { Run on promenade with } \\
25 \mathrm{BX} \text { programs }\end{array}$ & 60 \\
\hline 10 & Swim & 20 & $*$ & & Pilates & 30 & Rest & \\
\hline 11 & Swim & 20 & $*$ & & $\begin{array}{l}\text { Incline running and 5BX } \\
\text { program }\end{array}$ & 30 & Pilates & 30 \\
\hline 12 & $\begin{array}{l}\text { 5BX program with } \\
\text { Cycle }\end{array}$ & 30 & $*$ & & $\begin{array}{l}\text { Walk in Park followed by } \\
\text { Chi Gung Tao Yin }\end{array}$ & 40 & Run in park & 20 \\
\hline 13 & Pilates & 30 & Cycle & 15 & Cycle & 15 & Cycle & 15 \\
\hline 14 & $\begin{array}{l}\text { 5BX program with } \\
\text { Beach Walk }\end{array}$ & 30 & Incline Running & 15 & Run in park with cycle & 40 & Program end & \\
\hline 15 & $\begin{array}{l}\text { 5BX program with } \\
\text { Beach Walk }\end{array}$ & 30 & Sand Running & 15 & $\begin{array}{l}\text { 5BX program with } \\
\text { incline running }\end{array}$ & 20 & & \\
\hline 16 & & & & & Walk on sand & 15 & & \\
\hline 17 & Squash & 20 & Cycle & 35 & Rest & & & \\
\hline 18 & Rest & & Rest & & Rest & & & \\
\hline 19 & Rest & & Pilates & 40 & $\begin{array}{l}\text { Walk on promenade } \\
\text { and park }\end{array}$ & 60 & & \\
\hline 20 & $\begin{array}{l}\text { Beach walk with } \\
\text { 5BX program }\end{array}$ & 30 & Influenza & & $\begin{array}{l}\text { Incline running with } \\
\text { cycle }\end{array}$ & 30 & & \\
\hline
\end{tabular}




\begin{tabular}{|c|c|c|c|c|c|c|}
\hline 21 & $\begin{array}{l}\text { 5BX program with } \\
\text { Cycle }\end{array}$ & 30 & Influenza & & $\begin{array}{l}\text { Incline running followed } \\
\text { by } 5 \mathrm{BX} \text { program }\end{array}$ & 30 \\
\hline 22 & Pilates & 30 & Influenza & & Pilates & 30 \\
\hline 23 & $\begin{array}{l}\text { 5BX program with } \\
\text { Cycle }\end{array}$ & 30 & Influenza & & Beach Run & 20 \\
\hline 24 & $*$ & & $\begin{array}{l}\text { 5BX program } \\
\text { with cycle }\end{array}$ & 30 & $\begin{array}{l}\text { Incline running followed } \\
\text { by } 5 \mathrm{BX} \text { program }\end{array}$ & 30 \\
\hline 25 & $*$ & & Pilates & 40 & Rest & \\
\hline 26 & $*$ & & $\begin{array}{l}\text { Beach walk and } \\
\text { 5BX program }\end{array}$ & 30 & $\begin{array}{l}\text { Run in park followed by } \\
\text { swim }\end{array}$ & 40 \\
\hline 27 & $*$ & & $\begin{array}{l}\text { Cycle with 5BX } \\
\text { program }\end{array}$ & 30 & Cycle & 15 \\
\hline 28 & $*$ & & Rest & & Walk on the promenade & 40 \\
\hline 29 & $*$ & & Rest & & Rest & \\
\hline 30 & $*$ & & Rest & & Run on sand & 20 \\
\hline 31 & $*$ & & Rest & & Rest & \\
\hline
\end{tabular}

*Program temporarily discontinued for family visit.

Table 3. Exercise program summary

\begin{tabular}{llllll}
\hline Exercise & Borg Intensity Scale & February & March & April & May \\
\hline Cycle & 6 - severe breathlessness & 5 & 5 & 10 & 3 \\
Run & 5 - severe breathlessness & 1 & 2 & 13 & 5 \\
5BX & $4-$ somewhat severe & 10 & 2 & 5 & 4 \\
Swim & 3 - very slight & 2 & 1 & 1 & 1 \\
Walk & 3 - very slight & 4 & 2 & 6 & 3 \\
Pilates & 3 - very slight & 3 & 2 & 3 \\
\hline
\end{tabular}

Tables 2 and 3 provide detailed and summary evidence of the program, which appears to have been nicely balanced in terms of high intensity and low impact components. It should be noted that the client did not experience very severe or maximal breathlessness states of intensity.

\subsection{Qualitative Findings}

The client's verbatim experience of each exercise component follow. Experiences typically reflects some enjoyable, fun, flow and/or feel good quality.

Cycling: A sense of strength rooted to the ground. A sense of the earth and lower strength and energy. A sense of grounding and of stability. A sense of routine and of the repetitive nature of tasks. An opportunity to feel the heart change through the lower body. A creation of control and energy release through the legs.

Running: An experience of freedom and release of energy and strength into the environment. A way to clear the mind and consciousness and to feel at one and sense the body in a full and more conscious way. The movement of the body creating rhythm and repetitiveness. A way to entrance the mind and remove oneself from immediacy and stress. Sand and water underneath the feet. Cool water sensed on the feet. The natural environment and the ocean creating a type of oneness and fluidity in the body, mind and spirit. The sense of self as a living creature in a living world and an interconnectedness with the world. A sense of exertion of strength, release and completion leading to calm and stillness.

5BX: A sense of the holistic self. A time for the full body from head to toes. The strength of the upper, the neck, the arms and the back during the core session while the strength of the legs and heart during the lower body component. 
A sense of the body as its own form of resistance that may be used to create and change energy.

Swimming: An experience of the upper body of renewal and of cleansing. A feeling of immersion and of cleansing of the body, mind and the spirit. Exertion in the water and energy in the upper body guiding the self through the water to new places. A sense of being surrounded by matter and density and navigating through matter to new spaces. A sense of slow energy release and of slowly achieved objectives. A chance to breathe in a controlled and systemized sequence that allows the sensation of efficiency.

Walking: A sense of the environment and a sense of air and of breath. A feeling of freshness of new clean air. A feeling of renewal through breathing. A feeling of control of the breath and of controlled exertion. An encounter with nature and with its participants. A sense of the earth and its patterns of weather.

Pilates: Developed strength in the upper body but core mostly. The strength and energy released through the core into the other parts and places of the body. Feeling and sense of being close to the earth and of the lack of significance of being or feeling small on the ground. The idea of the world as a larger place and recognition of being a small part of a total existence was sensed. A sense of control over matter and the body as a centre of control over matter was sensed.

Squash: A sense or a return to the idea of a tit for tat activity with responses required in order to achieve release of tension. The lower body and legs as an energy force for reaction and for achievement. This was a once off event played with a relative. On the Borg intensity scale it was experienced as a 6 - severe breathlessness.

Chi-Gung Tao Yin: This exercise was experienced in terms of grounding and correct breathing and posture. Used as an anchor for breathing practice, relaxation and meditation. It is a form of moving yoga and was a regular practice before being succeeded by Pilates. The Tao yin has been a large influence in correct positioning of the spine for Pilates. I may have felt more strain had I not kept the spine straightening mentioned in Tao Yin in mind. On the Borg intensity scale it was experienced as a 0 - no breathlessness.

Rest: A feeling of rest and of calm. A sense of relaxation and withdrawal from energy releasing activities. A chance to store energy and reflect on energy released from the body. This is a very important component of any exercise program.

\subsubsection{Client Experience of the Program}

I began the program seeking an improvement in health and psychological areas in my daily life. A program was developed that focused on low impact and high energy activity. I used spinning as well as running and various other core strengthening activities. My fitness levels improved. My breathing and anaerobic strength has increased significantly. The aim was to reduce impact on the joints. I felt an improved sense of being and outlook towards the future and enjoyed the daily tasks involved in the exercises. There was an improved sense of balance in my bodily systems. I have felt more controlled and focused after completing this program and a sense of general wellbeing has entered my consciousness. The program was developed in consultation with a healthcare professional who allowed me to select the exercises that I wished to perform. A sequence was then selected in order to reduce the possibility of injury. Periods of at least 20 minutes for cycling and running were used with a specific sequence of repetitions. Core strength was built and improved with Pilates and the 5bx program. The activities during the day gave a strong sense of focus and direction of energy and often left me feeling stronger but also more relaxed. A higher level of consciousness was attained in performing these activities and a greater sense of health and well-being was the outcome.

Improved breathing and consciousness of the heart has found its way into other aspects and activities in daily life. Improved ability to control anxiety levels in stressful situations such as in examinations where during a recent exam, I was able to find more flow and rhythm in answering academic questions after initially feeling an elevated heart rate and in being in stressful conditions. During the mentoring and tutoring of students, I have found that the improved breathing has allowed for a more coherent approach to assisting students preparing for their exams. In running with a friend over distances, I was able to improve coherence and consciousness of the activity and remain in the moment and enjoy the activity and the natural surroundings. The program has improved multiple aspects of coherence in my life and has left me feeling positive and excited about the future. I feel that my ability to empathise and communicate with others has been improved. The program has been a source of enjoyment and has delivered a sense of pride in self and of self-worth. This has been of great value in developing and maintaining a positive frame of mind. The program has not only improved my physical strength and fitness but also renewed consciousness of the heart as the centre of being and of life. 


\subsubsection{Client Evaluation of the Program}

Based on my own individual preferences, I found the program to be flexible and adaptable depending upon mood, weather and physical body responses. The program can be adapted to create sustainability as with all cross training programs and minimise the risk of injury. Sufficient components were incorporated to ensure that a sense of newness in activities. I found the program to be invigorating. The program can be adapted to suit the needs of various individuals who face time and space constraints in their daily lives.

\subsection{Integrated Evaluation}

The client received health and exercise psychological counselling on a weekly basis over a period of three months. The counselling relationship reflected typical, mentor mentee type coaching, support and mutual companionship, with the client taking main direction and monitoring of all ongoing phases on the program. The counsellor provided theoretical and practical, health and exercise psychological coaching. Specific focus was on high intensity and low impact training using HeartMath coherence theory and praxis, for example, lending instructional resource material, demonstrating and practising Alexander, Pilates, yogic and chi-gung postural techniques. Emphasis was on individual, social and environmental coherence, health, resilience through listening to the heart, cultivating positive mood, and flexibly adapting the training program to the everyday requirements of life.

The health psychological counselling process was based on an excellent client counsellor relationship, which provided both the necessary and sufficient foundations for what was to become an effective program. Indicative of the excellent client counsellor relationship, the client rated the counselor as excellent on all 10 of the CARE scale measure 1) Making you feel at ease, 2) Letting you tell your "story", 3) Really listening, 4) Being interested in you as a whole person, 5) Fully understanding your concerns, 6) Showing care and compassion, 7) Being positive, 8) Explaining things clearly, 9) Helping you to take control, 10) Making a plan of action with you. Similarly the counsellor rated the client excellent in terms of program compliance, motivation and general involvement with all aspects and dimensions.

Documentation thus provides integrated, quantitative and qualitative, experiential and evaluative evidence of an effective, short term, health psychological case study incorporating high intensity and low impact cross training components. As pointed out by the client himself, the program can be adapted to suit the needs of various individuals who face time and space constraints in their daily lives. In addition to exercise adherence, sustainability and minimal injury risk, such programs tend to be highly effective as they are highly adaptable as well as intrinsically enjoyable and meaningful. With minimal client and/or coach tweaking for greater complexity, control, skills and challenges, they can virtually guarantee enjoyable and meaningful, zone and flow experiences.

\section{Competing Interests Statement}

The authors declare that there are no competing or potential conflicts of interest.

\section{References}

Balk, M., \& Shields, A. (2016). The art of running. London, England: Collins and Brown.

Biddle, S. J. H., \& Batterham, A. M. (2015). High-intensity interval exercise training for public health: a big HIT or shall we HIT it on the head? International Journal of Behavioural Nutrition and Physical Activity, 12, 95-103. https://doi.org/10.1186/s12966-015-0254-9

Borg, G. (1982) Psychophysical Bases of Perceived Exertion. Medicine Science in Sports Exercise, 14, 377-381. https://doi.org/10.1249/00005768-198205000-00012

Borg, E., Borg, G., Larssen, K., Letzter, M., \& Sundblad, B-M., (2010). An index for breathlessness and leg fatigue. Scandinavian Journal of Medicine and Science in Sports, 20, 644-650. https://doi.org/10.1111/j.1600-0838.2009.00985.x

Childre, D. L., Martin, H., Rozman, D., \& McCraty, R. (2016). Heart intelligence. Connecting with the intuitive guidance of the heart. HeartMath, CA: Waterfront Press.

Csikszentmihalyi, M. (1990). Flow. The psychology of optimal experience. New York, NY: HarperCollins.

Dean, J. E., Whelan, J. P., \& Meyers, A. W. (1990). An incredibly quick way to assess mood states: The incredibly short POMS. Paper presentation at the annual meeting of the Association for the Advancement of Applied Sport Psychology; San Antonio, TX.

Edwards, S. D. \& Fox, K.R. (2005). Promoting mental health: a multicultural human movement perspective. $\begin{array}{lllll}\text { International Journal of Mental Health Promotion, } & 7(3), & 18-29 .\end{array}$ https://doi.org/10.1080/14623730.2005.9721871 
Fetters, M. D., Curry, L. A., \& Creswell, J. W. (2017). Achieving integration in mixed methods designs - principles and practices. Health Service Research Journal, 48(6), 2134-2156. https://doi.org/10.1111/1475-6773.12117

Hankins, M. (2008). The reliability of the twelve-item general health questionnaire (GHQ-12) under realistic assumptions. BMC Public Health, 8, 355. https://doi.org/10.1186/1471-2458-8-355

Hoydal, K.L., \& Hareide, S. (2016). Evaluating and comparing the effect of high intensity interval training vs. low intense, longer-lasting training on endurance performance in recreational runners. International Journal of Applied Sports Sciences, 28(2), 101-110. https://doi.org/10.24985/ijass.2016.28.2.101

Kwan, B. M., Stevens, C. F., \& Bryan, A. D. (2017). What to expect when you're exercising: An experimental test of the anticipated affect-exercise relationship. Health Psychology, 36(4), 309-319. https://doi.org/10.1037/hea0000453

Mastura, J., Omar Fauzee, M.S., Bahaman, A.S., Rashid, S.A., \& Somchit, M.N. (2012). Effect of low-impact aerobic dance exercise on psychological health (stress) among sedentary women in Malaysia. Biology of Sport, 29(1), 63-69. https://doi.org/10.5604/20831862.984944

Mercer, S. W., Watt, G. C. M., Maxwell, M., \& Heaney, D. H. (2004). The development and preliminary validation of the Consultation and Relational Empathy (CARE) Measure: An empathy-based consultation process measure. Family Practice, 21(6), 699-705. https://doi.org/10.1093/fampra/cmh621

McNair, D. M., Lorr, M., \& Doppleman, L. F. (1971). Manual for the Profile of Mood States. San Diego, CA: Educational and Industrial Testing Service.

Noakes, T. (2011). Challenging beliefs. Cape Town, RSA: Zebra Press.

Ridder, H. G. (2017). The theory contribution of case study research designs. Business Research, 10, 281-305. https://doi.org/10.1007/s40685-017-0045-z

Rokka, S., Mavridis, G., \& Kouli, O. (2010). The impact of exercise intensity on mood state of participants in dance aerobics programs. Studies in Physical Culture and Tourism, 17(3), 241-245.

Smith, B.W., Dalen, J., Wiggins, K., Tooley, E., Christopher, P., \& Bernard, J. (2008). The Brief Resilience Scale: Assessing the ability to bounce back. International Journal of Behavioral Medicine, 15, 194-200. https://doi.org/10.1080/10705500802222972

Smith, B. W., Epstein, E. M., Ortiz, J. A., Christopher, P. J., \& Tooley, E. M. (2013). The foundations of resilience: What are the critical resources for bouncing back from stress? In S. Prince-Embury (Ed.), Resilience in Children, Adolescents, and Adults (pp. 167-188). New York, NY: Oxford. https://doi.org/10.1007/978-1-4614-4939-3_13

Starman, A. B. (2013). The case study as a type of qualitative research. Journal of Contemporary Educational Studies, 1, 28-43.

Sharkey, J. L. (2016) Exercise and mental health - implications for treatment: A review of the literature. Counseling \& Wellness Journal, 5, 1-8.

Terre Blanche, M., Durrheim, K., \& Painter, D. (2006). Research in practice; applied methods for the social sciences. Cape Town, RSA: University of Cape Town Press.

Wilber, K. (2000). Integral psychology. Boston, MA: Shambhala.

Wu, M. H., Lee, C. P., Hsu, S. C., Chang, C. M., \& Chen, C. Y. (2015). Effectiveness of high-intensity interval training on the mental and physical health of people with chronic schizophrenia. Neuropsychiatric Disease and Treatment, 11, 1255-1263. https://doi.org/10.2147/NDT.S81482

\section{Copyrights}

Copyright for this article is retained by the author(s), with first publication rights granted to the journal.

This is an open-access article distributed under the terms and conditions of the Creative Commons Attribution license (http://creativecommons.org/licenses/by/4.0/). 